\title{
New insights regarding HCV-NS5A structure/ function and indication of genotypic differences
}

\author{
Lilian HT Yamasaki ${ }^{1,4^{*}}$, Helen A Arcuri ${ }^{2}$, Ana Carolina G Jardim', Cintia Bittar ${ }^{1}$, Isabel Maria VG de Carvalho-Mello ${ }^{3}$ \\ and Paula Rahal ${ }^{1}$
}

\begin{abstract}
Background: HCV is prevalent throughout the world. It is a major cause of chronic liver disease. There is no effective vaccine and the most common therapy, based on Peginterferon, has a success rate of $~ 50 \%$. The mechanisms underlying viral resistance have not been elucidated but it has been suggested that both host and virus contribute to therapy outcome. Non-structural 5A (NS5A) protein, a critical virus component, is involved in cellular and viral processes.
\end{abstract}

Methods: The present study analyzed structural and functional features of 345 sequences of HCV-NS5A genotypes 1 or 3, using in silico tools.

Results: There was residue type composition and secondary structure differences between the genotypes. In addition, second structural variance were statistical different for each response group in genotype 3. A motif search indicated conserved glycosylation, phosphorylation and myristoylation sites that could be important in structural stabilization and function. Furthermore, a highly conserved integrin ligation site was identified, and could be linked to nuclear forms of NS5A. ProtFun indicated NS5A to have diverse enzymatic and nonenzymatic activities, participating in a great range of cell functions, with statistical difference between genotypes.

Conclusion: This study presents new insights into the HCV-NS5A. It is the first study that using bioinformatics tools, suggests differences between genotypes and response to therapy that can be related to NS5A protein features. Therefore, it emphasizes the importance of using bioinformatics tools in viral studies. Data acquired herein will aid in clarifying the structure/function of this protein and in the development of antiviral agents.

Keywords: Hepatitis C virus, Non-structural 5A protein, Bioinformatics, Genotype, Quasispecies, IFN response

\section{Introduction}

Hepatitis C is a major health problem; it is highly prevalent worldwide and has a high probability of persistence $[1,2]$. Chronic persistence can result in cirrhosis and hepatocellular carcinoma [3,4]. Hepatitis C virus (HCV) is member of the Flaviviridae family within the Hepacivirus genus, although many of its features are distinct from other family members including the structural organization of the protein and the 5'-cap independent translation [5].

On the basis of viral variability, HCV is classified into seven genotypes and more than 50 subtypes [6]. In

\footnotetext{
* Correspondence: Ihty@ibilce.unesp.br

'Department of Biology, Sao Paulo State University-UNESP, Sao Jose do Rio Preto, SP, Brazil

Full list of author information is available at the end of the article
}

addition, an infected patient will harbour different but related viral genomes known as quasispecies. This high variability can be explained by a combination of three factors: (1) viral RNA polymerase acts without proofreading [7]; (2) HCV has co-evolved with human populations for millions of years [8]; (3) the viral life cycle is fast, resulting in the production of approximately $1.3 \times$ 1012 virions per patient per day [9].

The HCV RNA genome translates a polyprotein that is cleaved by viral and host proteases to generate ten structural and non-structural proteins [10-12]. Among the non-structural proteins, NS5A is a phosphoprotein critical for the HCV life cycle. It is composed of approximately 447 amino acids and may participate in viral RNA replication, modulation of cell signaling pathways, interferon response, pathogenesis and apoptosis 
regulation. Its enzymatic functions and its complete structure have yet to be elucidated. However, evidence suggests that it functions through interaction with other HCV and host cell proteins [13-16].

NS5A is divided into three domains $[17,18]$. Domain I contains a membrane binding domain $[19,20]$ and a zinc finger domain that are essential for $\mathrm{HCV}$ replication [17]. Domain II and III are naturally unstructured, performing function by interacting with several proteins $[15,21]$.

The importance of NS5A protein in disease caused by hepatitis $C$ is unquestioned. However, difficulties with experimental methods used to determine the structures of highly flexible proteins have resulted in a poor understanding of the overall structure and functions of NS5A. Such difficulties have led to the development of bioinformatic tools that are helpful in obtaining reliable data for these types of proteins. Ab initio tools are also important for studying proteins with low or no homology, and can be used to compare them with experimentally determined structures.

In the present study, complete sequences from $\mathrm{HCV}$ NS5A genotypes 1 and 3 were analyzed. These sequences were obtained from Brazilian patients who showed different responses to Peginterferon (PegIFN) therapy. Using these sequences, the aims were to analyze structural and functional features. The knowledge obtained should aid in the design of new drugs and vaccines, and in developing other resources to improve $\mathrm{HCV}$ therapy.

\section{Results}

Amino acid composition and secondary structure of NS5A Therapy response did not differ according to the amino acids composition or the secondary structure type composition. However, considering the genotypes, the average percentages of alanine, glutamic acid, glutamine and tyrosine present in the NS5A protein were different between the genotypes $1 \mathrm{a}, 1 \mathrm{~b}$ and 3 . The average percentages of cysteine, valine and threonine differed between genotype 1 and 3 . All sequences obtained from genotype $1 \mathrm{~b}$ presented with $2 \%$ tyrosine (data not shown). Secondary structure analysis demonstrated that distribution of each secondary structure type followed a normal distribution. Statistical analysis ( $t$-test) suggests that the three secondary arrangements are high significant factors $(p-$ value $<.001)$ to differ the genotypes. Composition of helix, sheet or coil in percentage did not result in significant difference when we compared these three arrangements the therapy outcome responses (Figure 1A-C). In contrast, when we compared the variation of these compositions among the response groups, there is a great (and statistical) difference, especially in genotype 3. Test for equal variances (Bartlett's test and Levene's test) resulted in different variation behaviour comparing the three outcome responses sequences in genotype 3 (Figure $2 \mathrm{~A}-\mathrm{C})$. The same test applied for analysis intra-response group indicates that even when sequences are from different patients, if they are from the same therapy outcome group, they are not significantly different $(p>.05)$ (Table 1).

\section{Transmembrane regions and pattern/motif search}

MEMSAT3 analysis demonstrated that all NS5A and reference sequences contained a possible transmembrane region between residues 32 and 51, and Prosite recognized seven functional patterns in each NS5A sequence. No relationship was observed between therapy response or genotype and pattern number or motif location. Table 2 presents a summary of each conserved pattern/motif encountered in the NS5A analysis. Between two and seven $\mathrm{N}$-glycosylation sites were present within the same sequence. In two positions (69 and 268), this pattern was conserved in $90 \%$ of sequences; this motif was absent at these positions in $4 \%$ of cases. cAMP- and cGMP-dependent protein kinase phosphorylation sites were identified; $90 \%$ of sequences had a minimum of one such motif at position 357 , but $4 \%$ of sequences from one patient lacked this motif. Protein kinase $\mathrm{C}$ (PKC) phosphorylation sites were present in all sequences at positions 71 and 238. The number of these sites in the same sequence ranged from five to eight. Casein kinase II phosphorylation sites were recognized in non-conserved positions, being present between 4 and 8 times in the same sequence. Tyrosine kinase phosphorylation sites were identified in a conserved position (residue 122 or 123). N-myristoylation sites were present in various numbers and several positions, with NS5A sequences possessing between four and eight of these motifs in the same sequence. A cell attachment sequence (RGD sequence) was present in all sequences, conserved in number and position; NS5A sequences possessed this motif at position 48. Figure 3 summarizes the results of the MEMSAT3 and Prosite analyses in the reference sequence AF009606.

\section{Prediction of functional features}

ProtFun analysis results are detailed in Table 3. It indicated that the complete NS5A has properties similar to proteins which play role in regulatory functions, replication and transcription, central intermediary metabolism or purines/pyrimidines. All sequences were classified as an enzyme of unknown class, with the transcription regulation as the gene ontology category. Calculated chisquare test showed significant difference $(p<0.05)$ between therapy outcome groups and between genotypes related to functional category predicted, with statistical power level varying from 0.617 to 1 . 


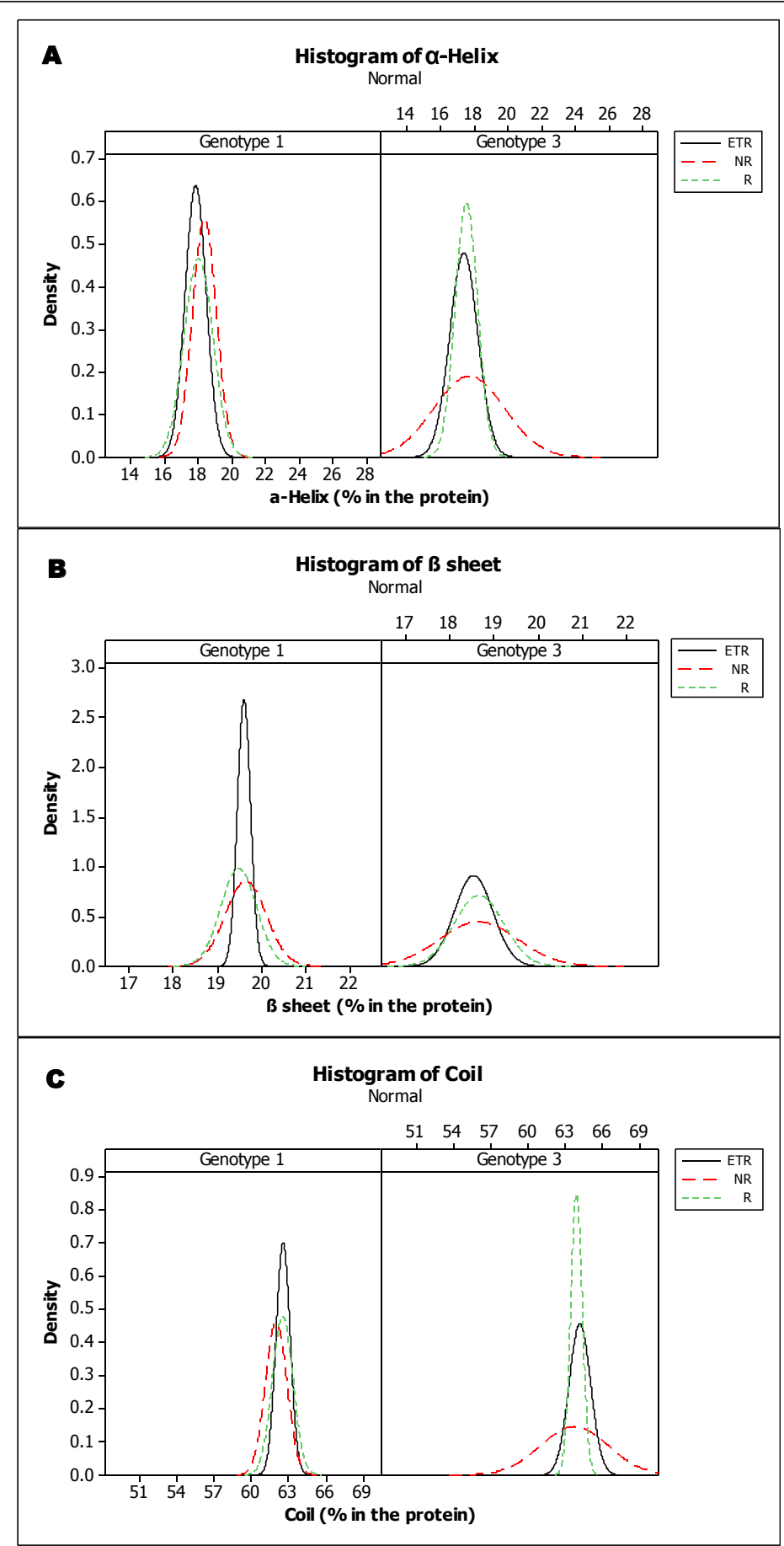

Figure 1 Statistical analysis in second Structure composition (\%) distribution of the NS5A sequences. Plot: Difference in helix (A), sheet (B) and coil (C) percentage in the NS5A protein between genotype 1 and 3/therapy outcome. X-axis describes the percentage of each second structure type in total protein; $y$-axis means density (number of sequences with correspond percentage/total number of sequences) ETR-End of therapy responder, NR-nonresponder, R-responder.

The results from NS5A domain I suggested that this region is related to the functional category of energy metabolism, with enzymatic activity from unknown class. For domain I, prediction of gene ontology category varied among transcription regulation, growth factor, immune response, transcription and none of these categories. To calculate the chi-square, categories below 5 sequences were excluded. Significant difference was 

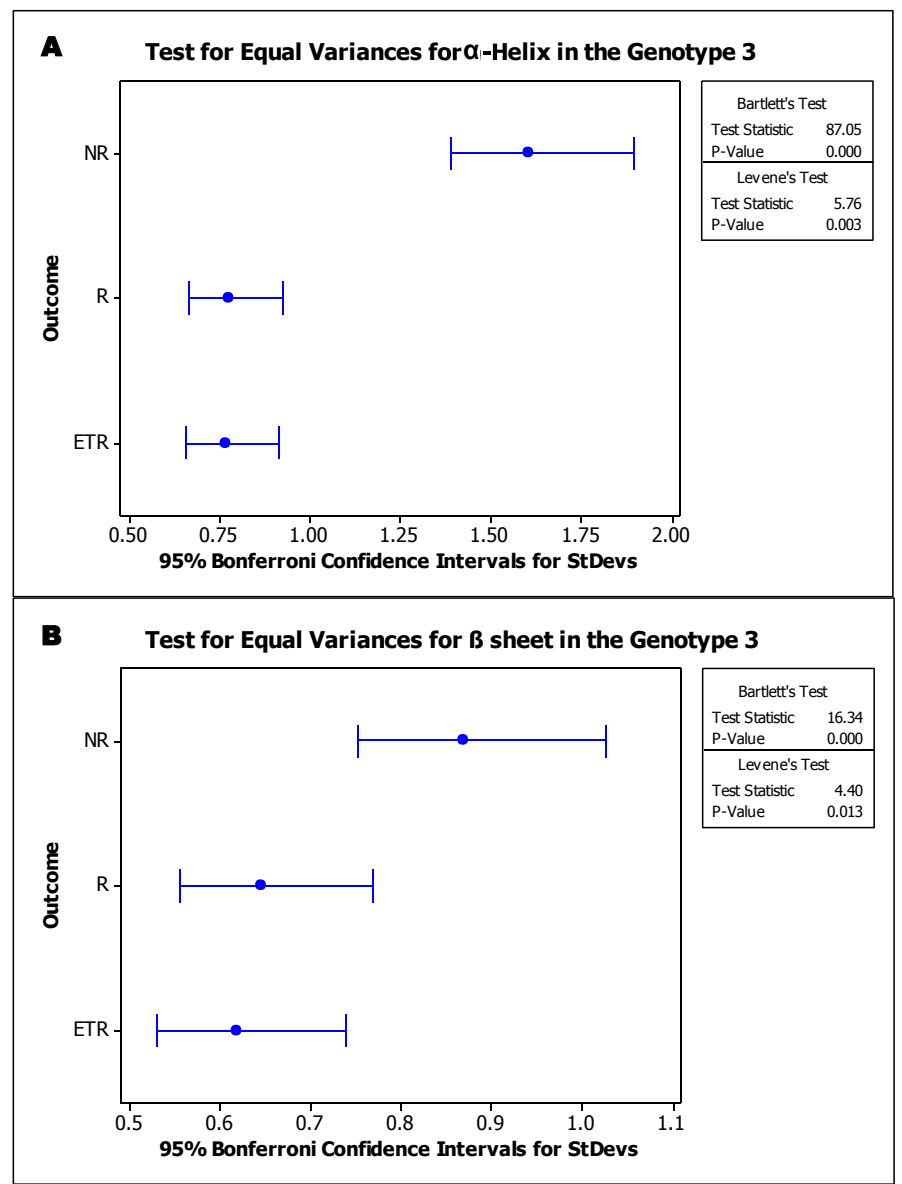

C Test for Equal Variances for Coil in the Genotype 3

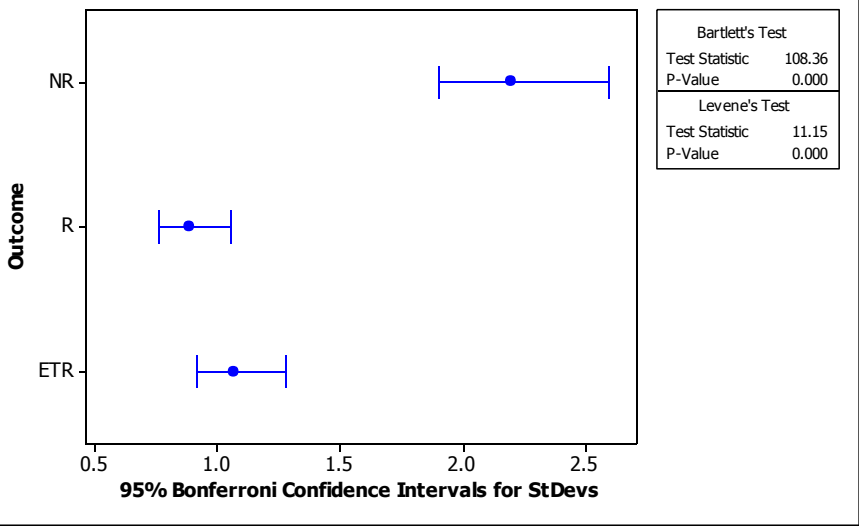

Figure 2 Statistical analysis in second structure composition (\%) variance of the NS5A genotype 3 sequences. Plot: Statistical results for helix $(\mathbf{A})$, sheet $(\mathbf{B})$ and coil $(\mathbf{C})$ variance in genotype 3. Square in the left shows the calculated values for each test. Note the variance different distribution in each response group. StDev-standard deviation.

observed between genotypes but not between therapy response groups, with statistical power of 0.999 .

Prediction for domain II sequences varied in functional category, enzymatic function and gene ontology category. Resulted functional category includes energy metabolism and translation, with statistical difference between therapy outcome groups (except between nonresponders-NR and end of therapy responders- ETR groups) and genotype. Enzymatic function prediction and gene ontology (GO) category prediction had significant difference between genotypes, with statistical power of 0.801 and 1 , respectively. 
Table 1 Statistical results (t-test) for comparison between genotype 1 and $\mathbf{3}$ secondary structure composition

\begin{tabular}{|c|c|c|c|c|c|}
\hline Genotype & No. of sequences ( $n$ ) & Mean & StDev & SE Mean & $p$-value \\
\hline & & \multicolumn{4}{|c|}{$\alpha$-helix } \\
\hline 1 & 109 & 18.06 & 0.52 & 0.05 & 0.00 \\
\hline \multirow[t]{2}{*}{3} & 143 & 17.51 & 0.41 & 0.03 & \\
\hline & & \multicolumn{4}{|c|}{$\beta$-sheet } \\
\hline 1 & 109 & 19.58 & 0.27 & 0.03 & 0.00 \\
\hline \multirow[t]{2}{*}{3} & 143 & 18.61 & 0.33 & 0.03 & \\
\hline & & \multicolumn{4}{|c|}{ Coil } \\
\hline 1 & 109 & 62.35 & 0.52 & 0.05 & 0.00 \\
\hline 3 & 143 & 63.88 & 0.38 & 0.03 & \\
\hline
\end{tabular}

StDev: Standard Deviation, SE: Standard Error

For domain III analysis, all the sequences were predicted to be similar to proteins related to transport and binding, with nonenzyme function. The gene ontology category varied among growth factor, immune response, stress response, hormone, voltage-gated ion channel and unknown. These differences were significant different between end of therapy responders (ETR) sequences and the other two outcome groups (non-respondersNR, responders-R) and between genotypes. Statistical power values were 0.6 and 1 , respectively.

\section{Discussion}

Infection with genotype 1 results in lower therapy success rates than other genotypes [22]. No previous study was found connecting NS5A amino acids composition or secondary structure type (Figure 1, 2 and Table 1) to this difference in response rate. The present study suggests that these two characteristics present genotypic differences. These differences could affect NS5A functions, by modifying its interactions with other viral and host proteins, or its stability. Consequently, these differences could affect viral resistance, replication and other properties linked to NS5A that differ among genotypes.

Indeed, some observations of the viral genotype specific features are reported between genotype 1 and 2 . Viral dynamics was the first property detected, in a study that collected viral load data in patients receiving
IFN therapy. Viral kinetics was greatly different. In genotype 1 infected patients, IFN effectiveness, free virion clearance rate and cell death rate were lower than genotype $2 \mathrm{HCV}$ hosts. In contrast, percentage of individuals that reached an undetectable level during 14 days of therapy was higher in genotype 2 infected individuals [23]. Our group also found in vivo indication of divergences in NS5A quasispecies composition and mutational profiles between genotypes 1 and 3 in baseline specimens $[24,25]$. Using the sequences derived from these studies, we showed that there is indication of structural and functional differences between NS5A-1a/ b and NS5A-3 (Table 3). In addition, at least for genotype 3 , there were differences in variance of structure between the different responses groups (Figure 2). This divergence is not observed when we compare the sequences extracted from patients with the same therapy response. Possibly resulting from the structural differences, the functional prediction profile was also different between genotypes.

In vivo and derived in silico results point to a relationship between NS5A and genotypic IFN response rate. However, in vitro researches results are still controversial. In 2008 , it was reported that cells infected by $2 \mathrm{a}-\mathrm{NS} 5 \mathrm{~A}-$ containing replicons presented lower degree of IFN antagonism than the counterpart containing 1b-NS5A. The same study also found suggestions that the V3 domain and the C-terminal region of the NS5A are related to IFN differential reaction [26]. Other study in 2010 did not reached similar conclusions. In this case, cells expressing $1 \mathrm{~b}$ and $2 \mathrm{a}$ NS5A protein presented analogous capability of IFN responses inhibition and IL-8 expression induction. The author suggests that other viral factors and/or host factors may be involved in the genotypic difference of $\mathrm{HCV}$ [27]. Posterior, it was also described that HCV with recombinant NS5A from different genotypes presents different sensibility to NS5A inhibitors, but not for IFN [28]. These hypothesis does support our group results, since it seems that NS5A has still numerous unknown direct and indirect interactions with host and viral proteins, consequence from the high structural flexibility observed in domains II and III of the protein $[15,21]$.

Table 2 Conservation of patterns/motifs predicted on NS5A, described in percentage of sequences

\begin{tabular}{|c|c|c|c|}
\hline Motif/pattern name & Presence & Conserved Positions & No. of sites in same sequence \\
\hline $\mathrm{N}$-glycosylation & $95,65 \%$ & $69,268(90 \%)$ & Two up to six \\
\hline cAMP/cGMP-dependent phosphorylation & $95,65 \%$ & $357(90,14 \%)$ & One up to two \\
\hline PKC phosphorylation & $100 \%$ & $71,238(98,84 \%)$ & Five up to eight \\
\hline CKII phosphorylation & $100 \%$ & - & Four up to eight \\
\hline Tyrosine kinase phosphorylation & $99,99 \%$ & 122 or $123(99,99 \%)$ & Four up to eight \\
\hline $\mathrm{N}$-myristoylation & $100 \%$ & - & Four up to eight \\
\hline Cell attachment sequence & $100 \%$ & $48(100 \%)$ & 1 \\
\hline
\end{tabular}




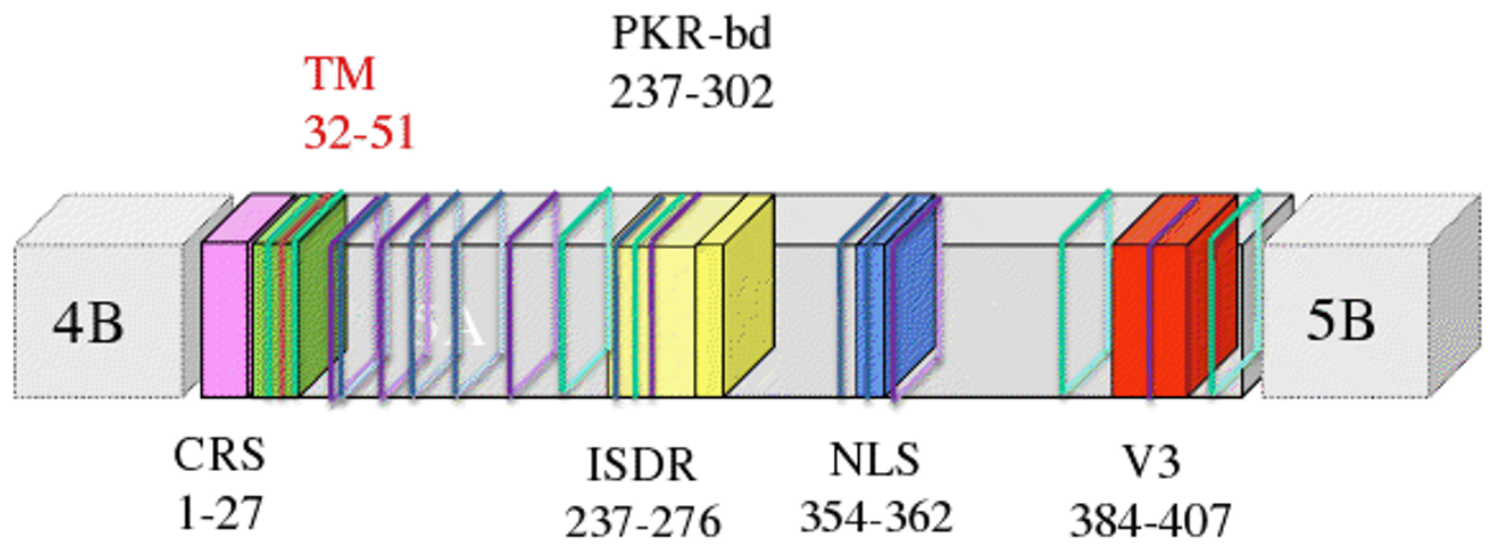

Figure 3 Results of MEMSAT3 and Prosite. Summary for NS5A reference AF009606. TM: transmembrane region, CRS: cytoplasmic retention site, PKR-bd: PKR binding site, NLS: nuclear localization site, V3: variable region 3. Lines-purple: n-glycosylation sites, blue: phosphorylation sites, green: $n$-myristoylation sites, orange: RGD site.

High structural flexibility is the key of the multifunctionality in promiscuous proteins [29]. The NS5A protein, as other promiscuous proteins, presents an intrinsic disorder. Recent studies showed that the domain III can be unfold or partially fold in helix [21], another feature of promiscuous proteins, which can present different conformations depending on the interactions made [29]. Our secondary structure prediction shows a high percentage of coils in NS5A, which results in the high structural flexibility of the NS5A. In addition with ProtFun predictions, we observed that NS5A may have genotypic differences in performed functions, varying also between the domains, with a great statistical difference $(p<.001)$ and power $(>.95)$ (Table 3$)$. Despite of the essential functions for HCV infection, NS5A from different genotypes may have different

Table 3 Statistical results for comparison between therapy outcome and genotype in ProtFun analysis

\begin{tabular}{|c|c|c|c|c|c|}
\hline Region & Feature & Comparison & Chi-square & $p$-value & Stat power \\
\hline \multirow[t]{5}{*}{ NS5A } & Functional category & Outcome & 18.832 & 0.004 & 0.711 \\
\hline & & $\mathrm{R}$ and $\mathrm{NR}$ & 10.697 & 0.013 & 0.617 \\
\hline & & $\mathrm{R}$ and ETR & 15.279 & 0.002 & 0.627 \\
\hline & & NR and ETR & 5.103 & 0.164 & 0.676 \\
\hline & & Genotype & 218.730 & 0.000 & 1 \\
\hline \multirow[t]{2}{*}{ Domain I } & $\mathrm{GO}^{*}$ & Outcome & 1.370 & 0.504 & 0.694 \\
\hline & & Genotype & 51.316 & 0.000 & 0.999 \\
\hline \multirow[t]{8}{*}{ Domain II } & Functional category & Outcome & 27.769 & 0.000 & 0.861 \\
\hline & & $\mathrm{R}$ and $\mathrm{NR}$ & 15.903 & 0.000 & 0.881 \\
\hline & & $\mathrm{R}$ and ETR & 16.776 & 0.000 & 0.581 \\
\hline & & NR and ETR & 0.241 & 0.623 & 0.663 \\
\hline & & Genotype & 21.755 & 0.000 & 0.780 \\
\hline & Non/enzyme & Genotype & 22.711 & 0.000 & 0.801 \\
\hline & $\mathrm{GO}$ & Outcome & 1.792 & 0.408 & 0.665 \\
\hline & & Genotype & 116.636 & 0.000 & 1 \\
\hline \multirow[t]{5}{*}{ Domain III } & $\mathrm{GO}^{*}$ & Outcome & 24.680 & 0.000 & 0.572 \\
\hline & & $\mathrm{R}$ and $\mathrm{NR}$ & 5.488 & 0.064 & 0.587 \\
\hline & & $\mathrm{R}$ and ETR & 11.307 & 0.010 & 0.616 \\
\hline & & ETR and NR & 12.374 & 0.006 & 0.609 \\
\hline & & Genotype & 54.217 & 0.000 & 0.998 \\
\hline
\end{tabular}


secondary functions. These functions may lead directly or indirectly to the different SVR rate in genotypes. Also, it would explain why NS5A from different genotypes have different behaviour when the mutational and quasispecies profile are analysed [24,25].

Prosite analysis demonstrated the presence of several potential co-and post-translational modification sites that are well conserved in the sequence, including Nglycosylation sites (Figure 3 and Table 2). Carbohydrate binding can confer a different function on a protein. For example, it can lead to the addition of epitopes that facilitate the recognition of other proteins [30,31]. There are no studies that describe glycosylation of NS5A, but in some viruses, glycosylated proteins can be essential for viral assembly [32]. Helenius (1994) demonstrated that glycosylation promoted an increase in solubility, and possibly in interactions with chaperones on the endoplasmatic reticulum, thereby affecting folding and stabilization of the protein. Proteins without this modification could assemble in a non-reversable form or exit the endoplasmatic reticulum [33]. N- and O-linked glycosylation are also described in non-reticulum compartments, such as nucleus and cytosol [34]. Since this discover, several cytosolic proteins involved in the process of adding carbohydrate to proteins were characterized $[35,36]$. Proteins which undergo these unusual glycosylation processes are linked with several functions, including nuclear membrane structure and transcription factors [37].

Following this hypothesis, NS5A glycosylation may be essential for maintaining its functional structure, as these modifications sequence appear to be conserved. In addition, this modification may play an important role in nuclear localization of NS5A mutants.

Potential phosphorylation sites were identified in NS5A. This modification has been experimentally described and is important for interaction with core proteins and for viral assembly [38]. Phosphorylation is a reversible modification process, and may be key to the multifunctionality of NS5A. Several proteins were identified as playing a role in NS5A phosphorylation including AKT, p70s6K, MEK, MKK1, CKI, CKIIe and Syk [39-41] but we found no study has described phosphorylation by PKC or cAMP-/cGMP-dependent protein kinase. These proteins are still candidates for this process, as details concerning NS5A phosphorylation have yet to be fully elucidated.

Possible myristoylation sites with qualitative conservation were recognized in NS5A. Covalent myristate binding is not reversible and alters the protein's hydrophobicity. In viral proteins such as Arenavirus and Arterivirus, this modification is related to functions such as protein cell localization and protein-protein interactions [42,43]. There are no studies describing myristoylation in the NS5A protein. However, we suggest that this process is important in structural/functional stabilization of NS5A. If experimental data demonstrated that these modifications are present in NS5A, these sites could be possible targets for new antiviral agents.

Interestingly, a cell attachment site (RGD) was present in all sequences between residues 48 and 52 . This region is inside the trasmembrane region predicted by MEMSAT3. RGD is a sequence for interaction with integrins, proteins located on the cell surface that act on cell-cell and cell-extracellular matrix interactions [44]. Although the intracellular functions of RGD require further investigation, studies concerning proprotein convertase 1 showed that this sequence is essential for correct folding in the endoplasmatic reticulum and transport to secretory glands [45].

Micelles with cyclic RGD peptides transfected into HeLa cells tend to congregate in the perinuclear region [46]. Therefore, the RGD sequence in NS5A genotypes 1 and 3 could have a role in (1) folding and intracellular transport and/or (2) nuclear and perinuclear localization. The NS5A protein has a functional nuclear location signal (NLS) at its carboxy terminal [47]. The complete protein form is predominantly located in the cytoplasm and/or in the perinuclear region $[47,48]$. However, forms in which the NS5A amino terminal region (residues 1-31) has been deleted predominate in the nucleus [49]. These deleted forms occur naturally during infection, resulting in cell caspase activity [50,51]. The function of these nuclear forms requires further study but they have been shown to be transcriptional regulators [52-54]. Furthermore, these forms can transport other proteins complexed with NS5A. The c-Raf protein interacts with the NS5A carboxy terminal and is detected in the cell nucleus with these deleted forms of the NS5A protein [54].

Regarding these studies, we suggest that the factors participating in NS5A nuclear localization are (1) deletion of the amino terminal region, which inhibits the NLS region; (2) presence of the NLS without mutations; (3) possible interactions between RGD and proteins related to transport through the nuclear envelope (4) possible glycosylation of NS5A similar to other nuclear functional proteins.

It is important to highlight that if other proteins are transported to the nucleus with c-Raf, nuclear NS5A could be important to the regulation and modulation of cell processes.

\section{Conclusions}

This research presents new insights regarding $\mathrm{HCV}$ NS5A genotypes 1 and 3. In addition, it demonstrates the importance of applying bioinformatic tools to the 
study of proteins that are difficult to investigate by other experimental procedures. There was no relationship between the response to therapy and primary structure, but for genotype 3 secondary structure variances were different between the three outcome groups. In addition, there is evidence that the primary/secondary structure differs among genotypes and that this could be important during the infection process. Functional prediction also indicated that NS5A may have functional difference between genotypes. Altogether, structural and functional properties show that the two genotypes behaviour during infection have differences. The acquired data can be compared with future experimental data regarding the NS5A protein and may help in developing new antiviral strategies, considering the genotypic differences present in Hepatitis $\mathrm{C}$ virus.

\section{Materials and methods Sequence bank}

The sequence bank included 345 NS5A complete sequences that were obtained from previous studies by our group $[24,25]$ and nine reference sequences from Genbank. These sequences were extracted from 23 Brazilian patients infected with $\mathrm{HCV}$ genotypes $1 \mathrm{a}, 1 \mathrm{~b}$ or 3 . The accession numbers in Genbank are EU309511aEU309673 for genotype 1; EU826174 to EU826233 and from EU826249 to EU826352 for genotype 3 . These samples comprised patients who had a sustained virological response (SVR), non response (NR) or end of treatment response (ETR) after conventional therapy based on Interferon (genotype 3 ) or Peginterferon (genotype 1) plus Ribavirin. Details of the study population are presented in Table 4. Redundant amino acid sequences were excluded, using the software LOCQSPEC 1.0 [55], resulting in 252 different sequences of complete NS5A.

\section{Amino acids and secondary structure analysis}

The percentage of each amino acid type was calculated and secondary structures investigated in all complete NS5A sequences from the sequence bank. These calculations were performed using the PROF program [56], using the Predict Protein Server http://www.predictprotein.org[57].

\section{Transmembrane region prediction}

Prediction of transmembrane regions was developed by the MEMSAT3 program [58]http://bioinf.cs.ucl.ac.uk/ psipred/. All NS5A sequences from the sequence bank were analyzed using this program.

\section{Prediction of sites}

All sequences were analyzed using the PROSITE program [59], from the Predict Protein Server [57]. Prosite
Table 4 Characteristics of the study population and number of NS5A different sequences

\begin{tabular}{cccc}
\hline Patient \# & Genotype & Therapy outcome & No. of sequences \\
\hline RF03 & 1A & ETR & 12 \\
RF37 & 1A & ETR & 11 \\
RF42 & 1B & ETR & 14 \\
RF45 & 1A & ETR & 13 \\
RF16 & 1A & NR & 13 \\
RF22 & 1B & NR & 5 \\
RF39 & 1B & NR & 3 \\
RF44 & 1B & NR & 11 \\
RF05 & 1B & R & 12 \\
RF35 & 1A & R & 10 \\
RF40 & 1A & R & 5 \\
RF20 & 3 & ETR & 14 \\
RF31 & 3 & ETR & 10 \\
RF109 & 3 & ETR & 13 \\
RF119 & 3 & ETR & 12 \\
RF07 & 3 & NR & 12 \\
RF60 & 3 & NR & 8 \\
RF75 & 3 & NR & 12 \\
RF145 & 3 & NR & 10 \\
RF80 & 3 & R & 14 \\
RF15 & 3 & R & 10 \\
RF18 & 3 & R & 15 \\
RF59 & 3 & - & 252 \\
TOTAL & - & & \\
\hline
\end{tabular}

is a pattern data bank, based on scientific publications or research describing the function of determined protein groups [59].

\section{Prediction of functional features}

Sequences were submitted to ProtFun 2.2 Server. The method is based on sequence derived protein features such as predicted post translational modifications, protein sorting signals and physical/chemical properties calculated from amino acid composition. This allows prediction of functionality for proteins which no homology can be found $[60,61]$. Acquired data were organized in tables (not shown) to posterior statistical analysis.

\section{Statistical analysis}

In order to establish if there were differences between the prediction results between the response groups or genotypes, test of homogeneity (chi-square test), $t$-test and equal variance test was calculated using the software MiniTab ${ }^{\circledR} 15$ (Minitab Inc., USA). Values under 5 (five) were excluded from statistical calculation, since these results could be deviation from the sample. Statistical power calculation was performed using online software Russ Lenth's power and sample size page [62]. 


\section{Acknowledgements}

This work was supported by grants from FAPESP, CNPq and CAPES

\section{Author details}

'Department of Biology, Sao Paulo State University-UNESP, Sao Jose do Rio Preto, SP, Brazil. ${ }^{2}$ Department of Clinical Medicine, Sao Paulo University-USP, Medicine College, Sao Paulo, SP, Brazil. ${ }^{3}$ Viral Immunology Laboratory, Butantan Institute, Sao Paulo, SP, Brazil. ${ }^{4}$ Rua Cristovao Colombo, 2265 Laboratorio de Estudos Genomicos, Jardim Nazareth, CEP: 15054-000, Sao Jose do Rio Preto, SP, Brazil.

\section{Authors' contributions}

LHTY carried out all experiments, acquisition of data, analysis and interpretation of data, and drafting the manuscript; HAA helped with the acquisition of data and interpretation of results; ACGJ, CB and IMVGCM participated in the study and the writing of the manuscript, PR conceived the study, participated in its analysis and coordination, and supplied suggestions for this manuscript. All authors read and approved the final manuscript.

\section{Competing interests}

The authors declare that they have no competing interests.

Received: 5 July 2011 Accepted: 12 January 2012

Published: 12 January 2012

\section{References}

1. Gale M Jr, Foy EM: Evasion of intracellular host defence by hepatitis $C$ virus. Nature 2005, 436:939-945.

2. Appel N, Zayas M, Miller S, Krijnse-Locker J, Schaller T, Friebe P, Kallis S, Engel U, Bartenschlager R: Essential role of domain III of nonstructural protein 5A for hepatitis C virus infectious particle assembly. PLoS Pathog 2008, 4:e1000035.

3. Alter HJ, Purcell RH, Shih JW, Melpolder JC, Houghton M, Choo QL, Kuo G Detection of antibody to hepatitis $C$ virus in prospectively followed transfusion recipients with acute and chronic non- $A$, non-B hepatitis. N Engl J Med 1989, 321:1494-1500.

4. Saito I, Miyamura T, Ohbayashi A, Harada H, Katayama T, Kikuchi S, Watanabe Y, Koi S, Onji M, Ohta Y, et al: Hepatitis C virus infection is associated with the development of hepatocellular carcinoma. Proc Natl Acad Sci USA 1990, 87:6547-6549.

5. Simmonds P: Genetic diversity and evolution of hepatitis $\mathrm{C}$ virus-15 years on. J Gen Virol 2004, 85:3173-3188.

6. Kuiken $C$, Simmonds $P$ : Nomenclature and numbering of the hepatitis $C$ virus. Methods Mol Biol 2009, 510:33-53.

7. Moradpour D, Cerny A, Heim MH, Blum HE: Hepatitis C: an update. Swiss Med Wkly 2001, 131:291-298.

8. Pybus OG, Charleston MA, Gupta S, Rambaut A, Holmes EC, Harvey PH: The epidemic behavior of the hepatitis C virus. Science 2001, 292:2323-2325.

9. Neumann AU, Lam NP, Dahari H, Gretch DR, Wiley TE, Layden TJ, Perelson AS: Hepatitis C viral dynamics in vivo and the antiviral efficacy of interferon-alpha therapy. Science 1998, 282:103-107.

10. Moradpour D, Blum HE: A primer on the molecular virology of hepatitis C. Liver Int 2004, 24:519-525.

11. Lyra AC, Fan X, Di Bisceglie AM: Molecular biology and clinical implication of hepatitis C virus. Braz J Med Biol Res 2004, 37:691-695.

12. Kamar N, Bendall RP, Peron JM, Cintas P, Prudhomme L, Mansuy JM, Rostaing L, Keane F, ljaz S, Izopet J, Dalton HR: Hepatitis E virus and neurologic disorders. Emerg Infect Dis 2011, 17:173-179.

13. Reed KE, Xu J, Rice CM: Phosphorylation of the hepatitis C virus NS5A protein in vitro and in vivo: properties of the NS5A-associated kinase. $J$ Virol 1997, 71:7187-7197.

14. Macdonald A, Harris M: Hepatitis C virus NS5A: tales of a promiscuous protein. J Gen Virol 2004, 85:2485-2502.

15. Liang $Y$, Ye $H$, Kang CB, Yoon HS: Domain 2 of nonstructural protein $5 \mathrm{~A}$ (NS5A) of hepatitis C virus is natively unfolded. Biochemistry 2007, 46:11550-11558.

16. Love RA, Brodsky O, Hickey MJ, Wells PA, Cronin CN: Crystal structure of a novel dimeric form of NS5A domain I protein from hepatitis C virus. J Virol 2009, 83:4395-4403.
17. Tellinghuisen TL, Marcotrigiano J, Gorbalenya AE, Rice CM: The NS5A protein of hepatitis C virus is a zinc metalloprotein. J Biol Chem 2004, 279:48576-48587.

18. Moradpour D, Brass V, Penin F: Function follows form: the structure of the N-terminal domain of HCV NS5A. Hepatology 2005, 42:732-735.

19. Brass V, Bieck E, Montserret R, Wolk B, Hellings JA, Blum HE, Penin F, Moradpour D: An amino-terminal amphipathic alpha-helix mediates membrane association of the hepatitis $C$ virus nonstructural protein $5 \mathrm{~A}$. J Biol Chem 2002, 277:8130-8139.

20. Liu S, Ansari IH, Das SC, Pattnaik AK: Insertion and deletion analyses identify regions of non-structural protein $5 \mathrm{~A}$ of Hepatitis $\mathrm{C}$ virus that are dispensable for viral genome replication. J Gen Virol 2006, 87:323-327.

21. Verdegem D, Badillo A, Wieruszeski JM, Landrieu I, Leroy A, Bartenschlager R, Penin F, Lippens G, Hanoulle X: Domain 3 of NS5A protein from the hepatitis $C$ virus has intrinsic \{alpha\}-helical propensity and is a substrate of Cyclophilin A. J Biol Chem 2011.

22. Wohnsland A, Hofmann WP, Sarrazin C: Viral determinants of resistance to treatment in patients with hepatitis C. Clin Microbiol Rev 2007, 20:23-38.

23. Neumann AU, Lam NP, Dahari H, Davidian M, Wiley TE, Mika BP, Perelson AS, Layden TJ: Differences in viral dynamics between genotypes 1 and 2 of hepatitis C virus. J Infect Dis 2000, 182:28-35.

24. Jardim AC, Yamasaki LH, de Queiroz AT, Bittar C, Pinho JR, Carareto CM, Rahal P, Mello IM: Quasispecies of hepatitis C virus genotype 1 and treatment outcome with peginterferon and ribavirin. Infect Genet Evol 2009, 9:89-698

25. Bittar C, Jardim AC, Yamasaki LH, de Queiroz AT, Carareto CM, Pinho JR, de Carvalho-Mello IM, Rahal P: Genetic diversity of NS5A protein from hepatitis $C$ virus genotype $3 a$ and its relationship to therapy response. BMC Infect Dis 2010, 10:36.

26. Tsai YH, Kuang WF, Lu TY, Kao JH, Lai MY, Liu CJ, Chen PJ, Hwang LH: The non-structural $5 \mathrm{~A}$ protein of hepatitis $\mathrm{C}$ virus exhibits genotypic differences in interferon antagonism. J Hepatol 2008, 49:899-907.

27. Kang SM, Won SJ, Lee GH, Lim YS, Hwang SB: Modulation of interferon signaling by hepatitis $C$ virus non-structural $5 \mathrm{~A}$ protein: implication of genotypic difference in interferon treatment. FEBS Lett 2010, 584:4069-4076

28. Scheel TK, Gottwein JM, Mikkelsen LS, Jensen TB, Bukh J: Recombinant HCV variants with NS5A from genotypes 1-7 have different sensitivities to an NS5A inhibitor but not interferon-alpha. Gastroenterology 2011, 140:1032-1042

29. Schreiber $G$, Keating AE: Protein binding specificity versus promiscuity. Curr Opin Struct Biol 2011, 21:50-61.

30. Taylor ME, Drickamer K: Structural requirements for high affinity binding of complex ligands by the macrophage mannose receptor. J Biol Chem 1993, 268:399-404

31. Petrescu AJ, Milac AL, Petrescu SM, Dwek RA, Wormald MR: Statistical analysis of the protein environment of $\mathrm{N}$-glycosylation sites: implications for occupancy, structure, and folding. Glycobiology 2004, 14:103-114

32. Graff J, Zhou YH, Torian U, Nguyen H, St Claire M, Yu C, Purcell RH, Emerson SU: Mutations within potential glycosylation sites in the capsid protein of hepatitis $E$ virus prevent the formation of infectious virus particles. J Virol 2008, 82:1185-1194

33. Helenius A: How N-linked oligosaccharides affect glycoprotein folding in the endoplasmic reticulum. Mol Biol Cell 1994, 5:253-265

34. Hart GW, Haltiwanger RS, Holt GD, Kelly WG: Glycosylation in the nucleus and cytoplasm. Annu Rev Biochem 1989, 58:841-874.

35. Pedemonte $\mathrm{CH}$, Sachs $\mathrm{G}$, Kaplan JH: An intrinsic membrane glycoprotein with cytosolically oriented n-linked sugars. Proc Natl Acad Sci USA 1990, 87:9789-9793.

36. Kreppel LK, Blomberg MA, Hart GW: Dynamic glycosylation of nuclear and cytosolic proteins. Cloning and characterization of a unique O-GIcNAc transferase with multiple tetratricopeptide repeats. J Biol Chem 1997, 272:9308-9315.

37. Hart GW: Dynamic O-linked glycosylation of nuclear and cytoskeletal proteins. Annu Rev Biochem 1997, 66:315-335.

38. Masaki T, Suzuki R, Murakami K, Aizaki H, Ishii K, Murayama A, Date T, Matsuura Y, Miyamura T, Wakita T, Suzuki T: Interaction of hepatitis $C$ virus nonstructural protein $5 \mathrm{~A}$ with core protein is critical for the production of infectious virus particles. J Virol 2008, 82:7964-7976. 
39. Huang Y, Staschke K, De Francesco R, Tan SL: Phosphorylation of hepatitis $C$ virus NS5A nonstructural protein: a new paradigm for phosphorylation-dependent viral RNA replication? Virology 2007, 364:1-9.

40. Tellinghuisen TL, Foss KL, Treadaway JC, Rice CM: Identification of residues required for RNA replication in domains II and III of the hepatitis C virus NS5A protein. J Virol 2008, 82:1073-1083.

41. Neddermann P: NS5A phosphorylation and hyperphosphorylation. Methods Mol Biol 2009, 510:95-110.

42. Gordon Jl, Duronio RJ, Rudnick DA, Adams SP, Gokel GW: Protein Nmyristoylation. J Biol Chem 1991, 266:8647-8650.

43. Farazi TA, Waksman $\mathrm{G}$, Gordon Jl: The biology and enzymology of protein N-myristoylation. J Biol Chem 2001, 276:39501-39504.

44. Ruoslahti E, Pierschbacher MD: Arg-Gly-Asp: a versatile cell recognition signal. Cell 1986, 44:517-518.

45. Rovere C, Luis J, Lissitzky JC, Basak A, Marvaldi J, Chretien M, Seidah NG: The RGD motif and the C-terminal segment of proprotein convertase 1 are critical for its cellular trafficking but not for its intracellular binding to integrin alpha5beta1. J Biol Chem 1999, 274:12461-12467.

46. Oba M, Aoyagi K, Miyata K, Matsumoto Y, Itaka K, Nishiyama N, Yamasaki Y, Koyama H, Kataoka K: Polyplex micelles with cyclic RGD peptide ligands and disulfide cross-links directing to the enhanced transfection via controlled intracellular trafficking. Mol Pharm 2008, 5:1080-1092.

47. Ide Y, Zhang L, Chen M, Inchauspe G, Bahl C, Sasaguri Y, Padmanabhan R: Characterization of the nuclear localization signal and subcellular distribution of hepatitis C virus nonstructural protein NS5A. Gene 1996, 182:203-211.

48. Kim JE, Song WK, Chung KM, Back SH, Jang SK: Subcellular localization of hepatitis C viral proteins in mammalian cells. Arch Virol 1999, 144:329-343.

49. Song J, Nagano-Fujii M, Wang F, Florese R, Fujita T, Ishido S, Hotta H: Nuclear localization and intramolecular cleavage of $\mathrm{N}$-terminally deleted NS5A protein of hepatitis C virus. Virus Res 2000, 69:109-117.

50. Hidajat R, Nagano-Fujii M, Deng L, Hotta H: Cleavage of the hepatitis $C$ virus NS5A protein by caspase- 3 in the interferon sensitivity-determining region in a sequence-dependent manner. Kobe J Med Sci 2004, 50:153-166.

51. Kalamvoki M, Georgopoulou U, Mavromara P: The NS5A protein of the hepatitis $C$ virus genotype $1 \mathrm{a}$ is cleaved by caspases to produce $\mathrm{C}$ terminal-truncated forms of the protein that reside mainly in the cytosol. J Biol Chem 2006, 281:13449-13462.

52. Tanimoto A, Ide Y, Arima N, Sasaguri Y, Padmanabhan R: The amino terminal deletion mutants of hepatitis $C$ virus nonstructural protein NS5A function as transcriptional activators in yeast. Biochem Biophys Res Commun 1997, 236:360-364.

53. Fukuma T, Enomoto N, Marumo F, Sato C: Mutations in the interferonsensitivity determining region of hepatitis $C$ virus and transcriptional activity of the nonstructural region 5A protein. Hepatology 1998, 28:1147-1153.

54. Sauter D, Himmelsbach K, Kriegs M, Carvajal Yepes M, Hildt E: Localization determines function: $\mathrm{N}$-terminally truncated NS5A fragments accumulate in the nucleus and impair HCV replication. J Hepatol 2009, 50:861-871.

55. Marucci EA, Zafalon GF, Jardim AC, Yamasaki LH, Bittar C, Rahal P, Machado JM: Routine libraries for pattern recognition in quasispecies. Genet Mol Res 2008, 7:970-981.

56. Rost B, Sander C: Improved prediction of protein secondary structure by use of sequence profiles and neural networks. Proc Natl Acad Sci USA 1993, 90:7558-7562.

57. Rost B, Yachdav G, Liu J: The predictprotein server. Nucleic Acids Res 2004, 32:W321-W326.

58. Jones DT: Improving the accuracy of transmembrane protein topology prediction using evolutionary information. Bioinformatics 2007, 23:538-544

59. Bairoch A, Bucher P, Hofmann K: The PROSITE database, its status in 1997. Nucleic Acids Res 1997, 25:217-221.

60. Jensen L, Gupta R, Blom N, Devos D, Tamames J, Kesmir C, Nielsen $H$, Staerfeldt HH, Rapacki K, Workman C, et al: Prediction of human protein function from post-translational modifications and localization features. $J$ Mol Biol 2002, 319:1257-1265.

61. Jensen $\sqcup$, Ussery DW, Brunak S: Functionality of system components: conservation of protein function in protein feature space. Genome Res 2003, 13:2444-2449.
62. Lenth RV: Java Applets for Power and Sample Size [Computer software]. Java Applets for Power and Sample Size 2006-9[http://www.stat.uiowa.edu/ rlenth/Power/].

doi:10.1186/1743-422X-9-14

Cite this article as: Yamasaki et al:: New insights regarding HCV-NS5A structure/function and indication of genotypic differences. Virology Journal 2012 9:14.

\section{Submit your next manuscript to BioMed Central and take full advantage of:}

- Convenient online submission

- Thorough peer review

- No space constraints or color figure charges

- Immediate publication on acceptance

- Inclusion in PubMed, CAS, Scopus and Google Scholar

- Research which is freely available for redistribution

Submit your manuscript at www.biomedcentral.com/submit
Ciomed Central 